\title{
Thermophysical Properties at Critical and Supercritical Conditions
}

\author{
Igor Pioro and Sarah Mokry \\ University of Ontario Institute of Technology
}

Canada

\section{Introduction}

Prior to a general discussion on specifics of thermophysical properties at critical and supercritical pressures it is important to define special terms and expressions used at these conditions. For better understanding of these terms and expressions Fig. 1 is shown below.

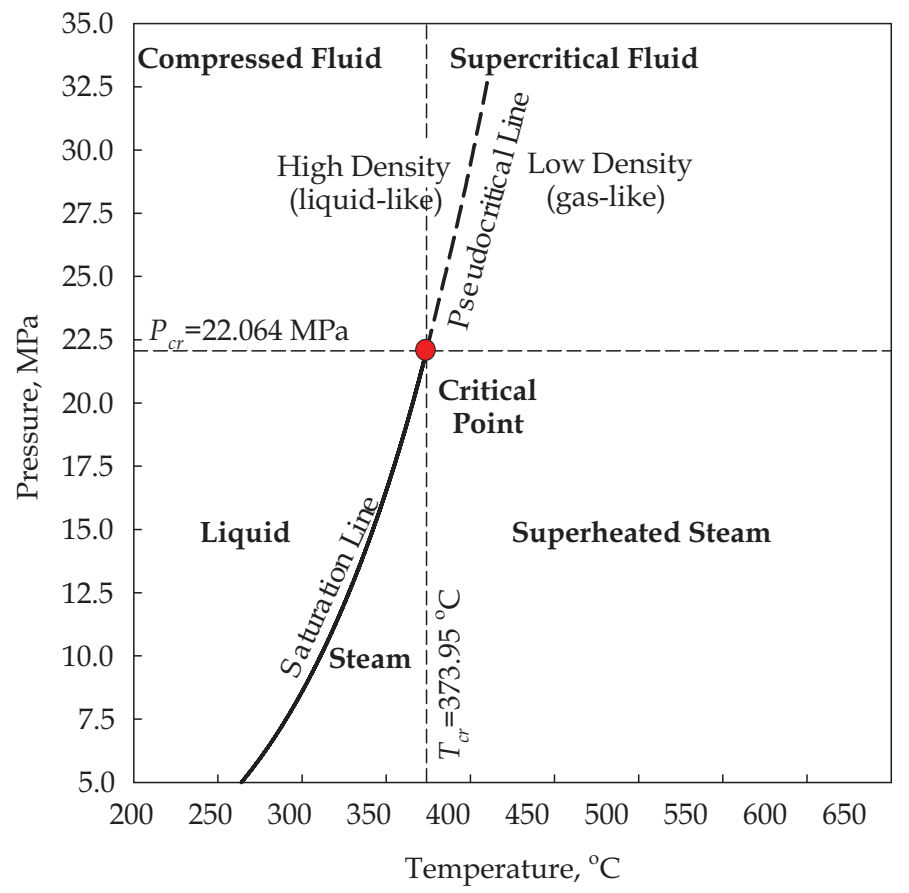

Fig. 1. Pressure-Temperature diagram for water.

Definitions of selected terms and expressions related to critical and supercritical regions Compressed fluid is a fluid at a pressure above the critical pressure, but at a temperature below the critical temperature. 
Critical point (also called a critical state) is a point in which the distinction between the liquid and gas (or vapour) phases disappears, i.e., both phases have the same temperature, pressure and volume or density. The critical point is characterized by the phase-state parameters $T_{c r}, P_{c r}$ and $V_{c r}$ (or $\left.\rho_{c r}\right)$, which have unique values for each pure substance.

Near-critical point is actually a narrow region around the critical point, where all thermophysical properties of a pure fluid exhibit rapid variations.

Pseudocritical line is a line, which consists of pseudocritical points.

Pseudocritical point (characterized with $P_{p c}$ and $T_{p c}$ ) is a point at a pressure above the critical pressure and at a temperature $\left(T_{p c}>T_{c r}\right)$ corresponding to the maximum value of the specific heat at this particular pressure.

Supencritical fluid is a fluid at pressures and temperatures that are higher than the critical pressure and critical temperature. However, in the present chapter, a term supercritical fluid includes both terms - a supercritical fluid and compressed fluid.

Supencritical "steam" is actually supercritical water, because at supercritical pressures fluid is considered as a single-phase substance. However, this term is widely (and incorrectly) used in the literature in relation to supercritical "steam" generators and turbines.

Superheated steam is a steam at pressures below the critical pressure, but at temperatures above the critical temperature.

\section{Historical note on using supercritical-pressure fluids}

The use of supercritical fluids in different processes is not new and has not been invented by humans. Mother Nature has been processing minerals in aqueous solutions at near or above the critical point of water for billions of years (Levelt Sengers, 2000). Only in the late 1800s, scientists started to use this natural process, called hydrothermal processing in their labs for creating various crystals. During the last 50 - 60 years, this process (operating parameters water pressures from 20 to $200 \mathrm{MPa}$ and temperatures from 300 to $500^{\circ} \mathrm{C}$ ) has been widely used in the industrial production of high-quality single crystals (mainly gem stones) such as quartz, sapphire, titanium oxide, tourmaline, zircon and others.

First works devoted to the problem of heat transfer at supercritical pressures started as early as the 1930s. Schmidt and his associates investigated free-convection heat transfer of fluids at the near-critical point with the application to a new effective cooling system for turbine blades in jet engines. They found that the free convection heat transfer coefficient at the near-critical state was quite high, and decided to use this advantage in single-phase thermosyphons with an intermediate working fluid at the near-critical point (Pioro and Pioro, 1997).

In the 1950s, the idea of using supercritical water appeared to be rather attractive for thermal power industry. The objective was increasing the total thermal efficiency of coalfired power plants. At supercritical pressures there is no liquid-vapour phase transition; therefore, there is no such phenomenon as Critical Heat Flux (CHF) or dryout. Only within a certain range of parameters a deteriorated heat transfer may occur. Work in this area was mainly performed in the former USSR and in the USA in the 1950s - 1980s (International Encyclopedia of Heat \& Mass Transfer, 1998).

In general, the total thermal efficiency of modern thermal power plants with subcriticalparameters steam generators is about $36-38 \%$, but reaches $45-50 \%$ with supercritical parameters, i.e., with a "steam" pressure of 23.5 - $26 \mathrm{MPa}$ and inlet turbine temperature of $535-585^{\circ} \mathrm{C}$ thermal efficiency is about $45 \%$ and even higher at ultra-supercritical parameters $\left(25-35 \mathrm{MPa}\right.$ and $600-700^{\circ} \mathrm{C}$ ) (see Fig. 2). 


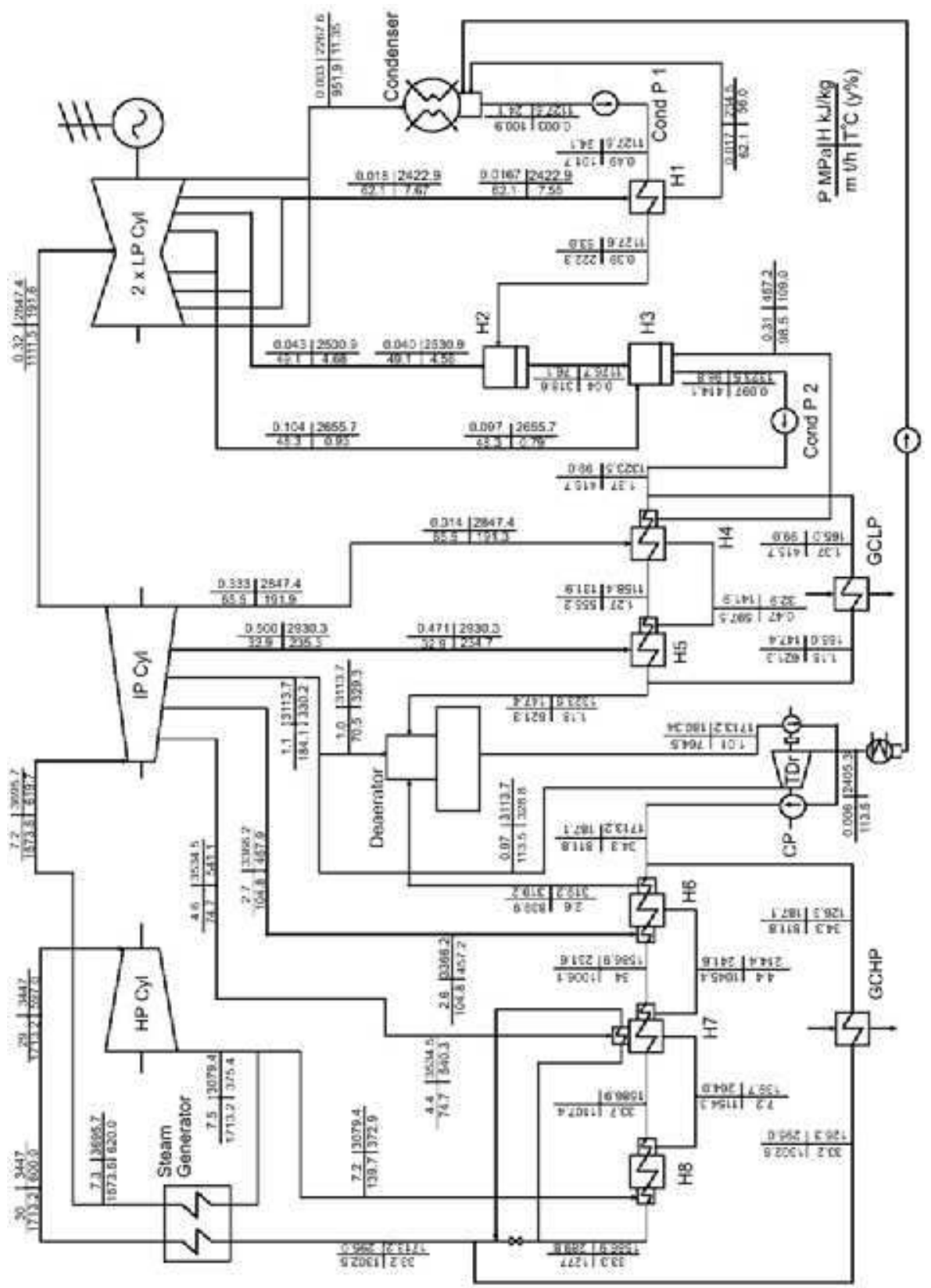

Cyl - Cylinder; H - Heat exchanger (feedwater heater); CP - Circulation Pump; TDr - Turbine Drive; Cond P - Condensate Pump; GCHP - Gas Cooler of High Pressure; and GCLP - Gas Cooler of Low Pressure.

Fig. 2. Single-reheat-regenerative cycle $600-\mathrm{MW}_{\mathrm{el}}$ Tom'-Usinsk thermal power plant (Russia) layout (Kruglikov et al., 2009). 
At the end of the 1950s and the beginning of the 1960s, early studies were conducted to investigate a possibility of using supercritical water in nuclear reactors (Pioro and Duffey, 2007). Several designs of nuclear reactors using supercritical water were developed in Great Britain, France, USA, and the former USSR. However, this idea was abandoned for almost 30 years with the emergence of Light Water Reactors (LWRs) and regained interest in the 1990s following LWRs' maturation.

Currently, SuperCritical Water-Cooled nuclear Reactor (SCWR) concepts are one of six options included into the next generation or Generation IV nuclear systems. The SCWR concepts therefore follow two main types, the use of either: (a) a large reactor pressure vessel (Fig. 3) with a wall thickness of about $0.5 \mathrm{~m}$ to contain the reactor core (fuelled) heat source, analogous to conventional PWRs and BWRs, or (b) distributed pressure tubes or channels analogous to conventional CANDU ${ }^{\circledR 1}$ nuclear reactors (Fig. 4). In general, mainly thermal-spectrum SCWRs are currently under development worldwide. However, several concepts of fast SCWRs are also considered (Oka et al., 2010; Pioro and Duffey, 2007).

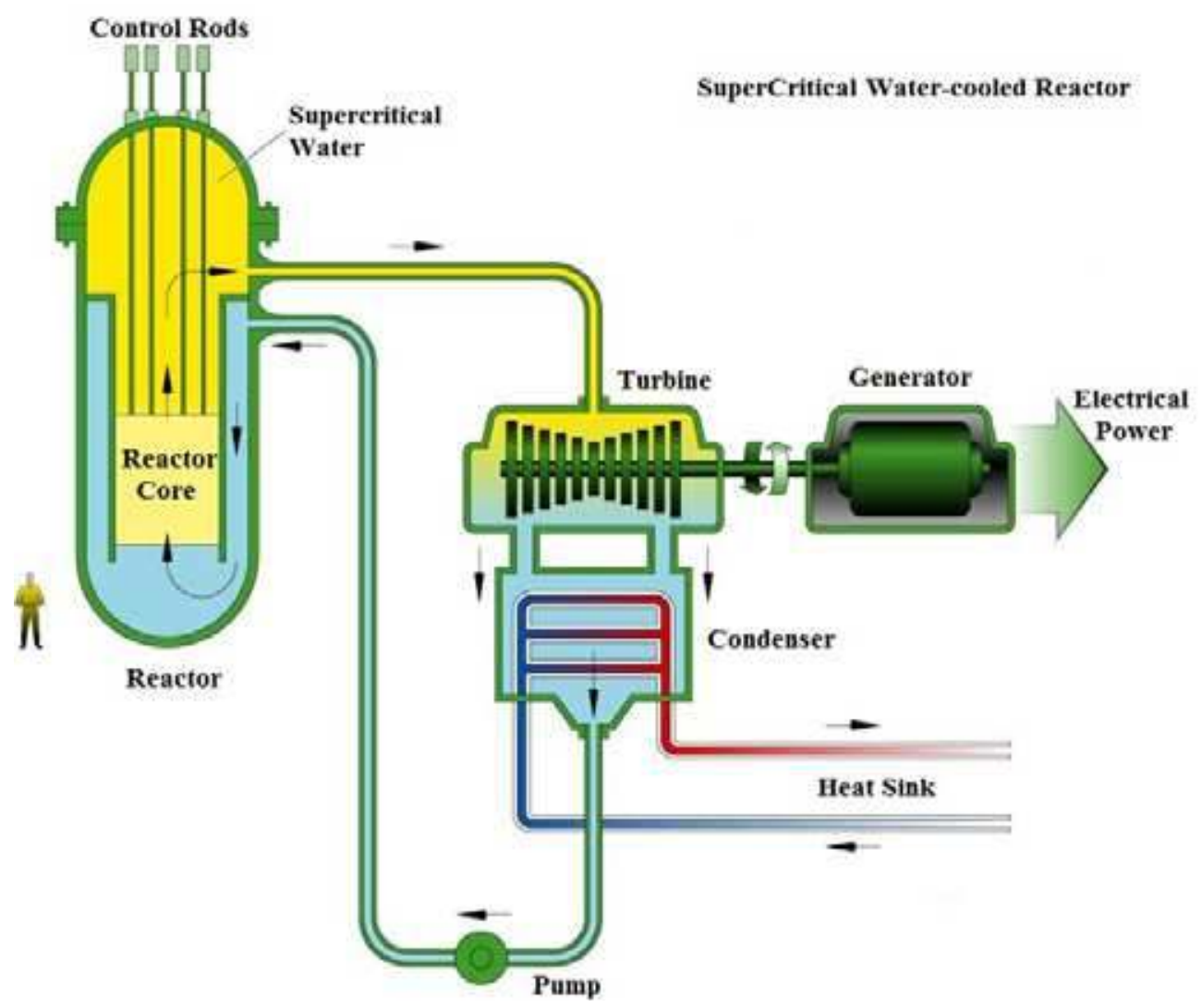

Fig. 3. Pressure-vessel SCWR schematic (courtesy of DOE USA).

${ }^{1}$ CANDU $^{\circledR}$ (CANada Deuterium Uranium) is a registered trademark of Atomic Energy of Canada Limited (AECL). 


\section{Multiple products are key to sustainable}

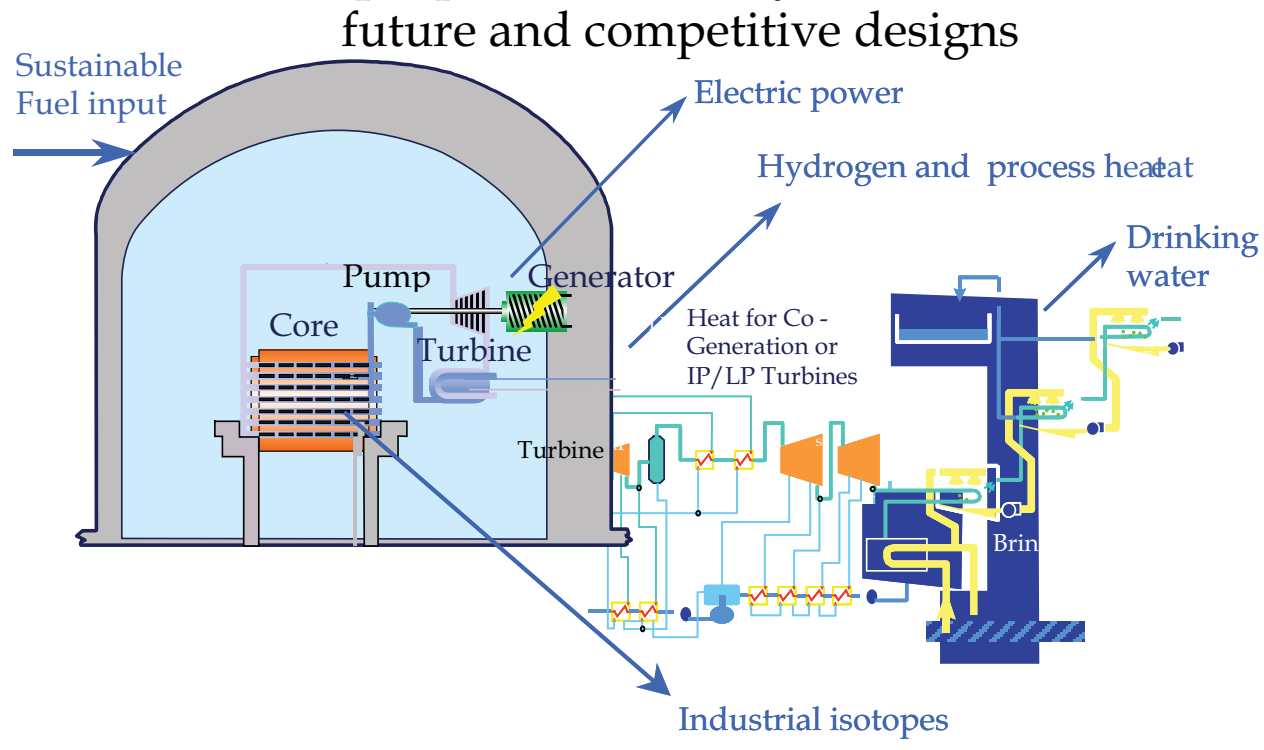

Fig. 4. General scheme of pressure-channel SCW CANDU reactor: IP - intermediatepressure turbine and LP - low-pressure turbine (courtesy of Dr. Duffey, AECL).

Use of supercritical water in power-plant steam generators is the largest application of a fluid at supercritical pressures in industry. However, other areas exist in which supercritical fluids are used or will be implemented in the near future (Pioro and Duffey, 2007):

- using supercritical carbon-dioxide Brayton cycle for Generation IV Sodium Fast Reactors (SFRs), Lead-cooled Fast Reactors (LFRs) (Fig. 5) and High Temperature helium-cooled thermal Reactors (HTRs);

- $\quad$ using supercritical carbon dioxide for cooling printed circuits;

- using near-critical helium to cool coils of superconducting electromagnets, superconducting electronics and power-transmission equipment;

- $\quad$ using supercritical hydrogen as a fuel for chemical and nuclear rockets;

- using supercritical methane as a coolant and fuel for supersonic transport;

- using liquid hydrocarbon coolants and fuels at supercritical pressures in cooling jackets of liquid rocket engines and in fuel channels of air-breathing engines;

- using supercritical carbon dioxide as a refrigerant in air-conditioning and refrigerating systems;

- using a supercritical cycle in the secondary loop for transformation of geothermal energy into electricity;

- using SuperCritical Water Oxidation (SCWO) technology for treatment of industrial and military wastes;

- $\quad$ using carbon dioxide in the Supercritical Fluid Leaching (SFL) method for removal uranium from radioactive solid wastes and in decontamination of surfaces; and

- using supercritical fluids in chemical and pharmaceutical industries in such processes as supercritical fluid extraction, supercritical fluid chromatography, polymer processing and others. 
The most widely used supercritical fluids are water and after that carbon dioxide, helium and refrigerants (Pioro and Duffey, 2007). Usually, carbon dioxide and refrigerants are considered as modeling fluids instead of water due to significantly lower critical pressures and temperatures, which decrease complexity and costs of thermalhydraulic experiments. Therefore, knowledge of thermophysical-properties specifics at critical and supercritical pressures is very important for safe and efficient use of fluids in various industries.

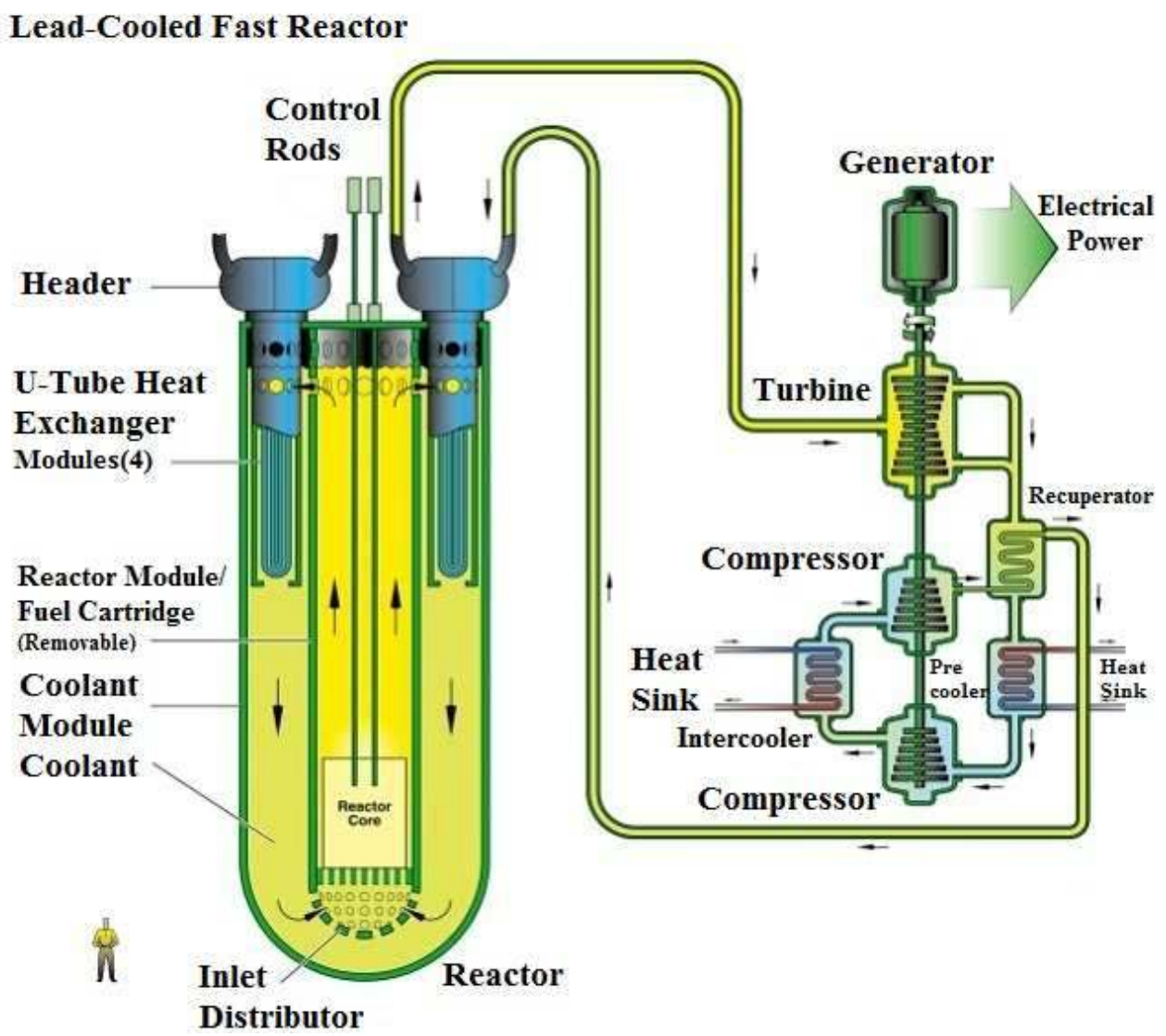

Fig. 5. Lead-cooled Fast Reactor with supercritical carbon dioxide Brayton cycle (courtesy of DOE USA).

\section{Thermophysical properties at critical and supercritical pressures}

General trends of various properties near the critical and pseudocritical points (Pioro, 2008; Pioro and Duffey, 2007) can be illustrated on a basis of those of water (Figs. 6-9). Figure 6 shows variations in basic thermophysical properties of water at the critical $\left(P_{c r}=22.064\right.$ $\mathrm{MPa})$ and three supercritical pressures $(P=25.0,30.0$, and $35.0 \mathrm{MPa})$ (also, in addition see Fig. 7). Thermophysical properties of water and other 83 fluids and gases at different pressures and temperatures, including critical and supercritical regions, can be calculated 
using the NIST REFPROP software (2007). Critical parameters of selected fluids are listed in Table 1.

At the critical and supercritical pressures a fluid is considered as a single-phase substance in spite of the fact that all thermophysical properties undergo significant changes within the critical and pseudocritical regions. Near the critical point, these changes are dramatic (see Fig. 6). In the vicinity of pseudocritical points, with an increase in pressure, these changes become less pronounced (see Figs. 6 and 9).

\begin{tabular}{|l|c|c|c|}
\hline \multicolumn{1}{|c|}{ Fluid } & $\begin{array}{c}P_{c r} \\
\mathrm{MPa}\end{array}$ & $\begin{array}{c}T_{c r}, \\
{ }^{\circ} \mathrm{C}\end{array}$ & $\begin{array}{c}\rho_{c r}, \\
\mathrm{~kg} / \mathrm{m}^{3}\end{array}$ \\
\hline Carbon dioxide $\left(\mathrm{CO}_{2}\right)$ & 7.3773 & 30.978 & 467.6 \\
\hline Freon-12 (Di-chloro-di-fluoro-methane, $\left.\mathrm{CCl}_{2} \mathrm{~F}_{2}\right)$ & 4.1361 & 111.97 & 565.0 \\
\hline Freon-134a (1,1,1,2-tetrafluoroethane, $\left.\mathrm{CH}_{2} \mathrm{FCF}_{3}\right)$ & 4.0593 & 101.06 & 511.9 \\
\hline Water $\left(\mathrm{H}_{2} \mathrm{O}\right)$ & 22.064 & 373.95 & 322.39 \\
\hline
\end{tabular}

Table 1. Critical parameters of selected fluids (Pioro and Duffey, 2007).

Also, it can be seen that properties such as density and dynamic viscosity undergo a significant drop (near the critical point this drop is almost vertical) within a very narrow temperature range (see Figs. $6 a, b$ and 7 ), while the kinematic viscosity and specific enthalpy undergo a sharp increase (see Figs. 6d,g and 7). The volume expansivity, specific heat, thermal conductivity and Prandtl number have peaks near the critical and pseudocritical points (see Figs. 6c,e,f,h, 7 and 8). Magnitudes of these peaks decrease very quickly with an increase in pressure (see Fig. 9). Also, "peaks" transform into "humps" profiles at pressures beyond the critical pressure. It should be noted that the dynamic viscosity, kinematic viscosity and thermal conductivity undergo through the minimum right after the critical and pseudocritical points (see Fig. 6b,d,f).

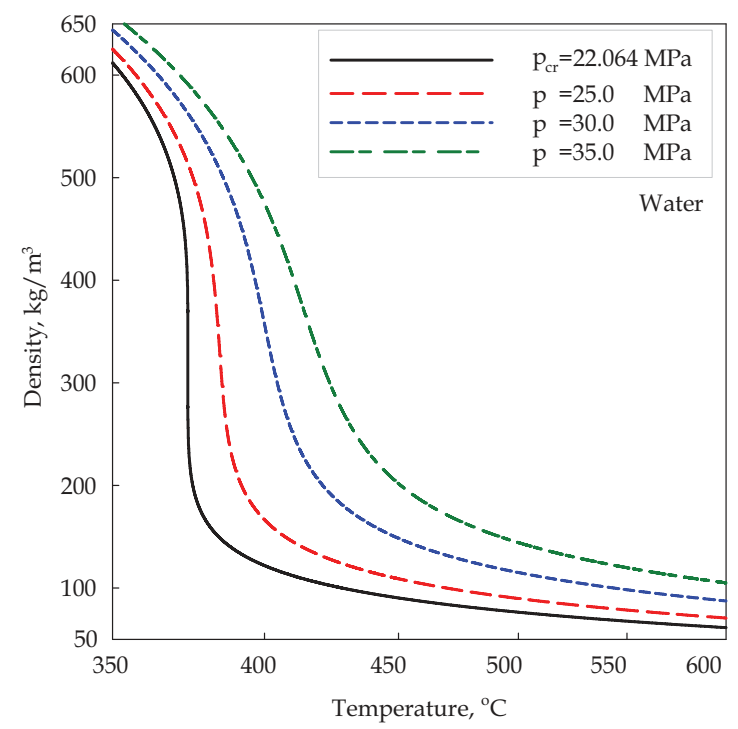

Fig. 6a. Density vs. Temperature: Water. 


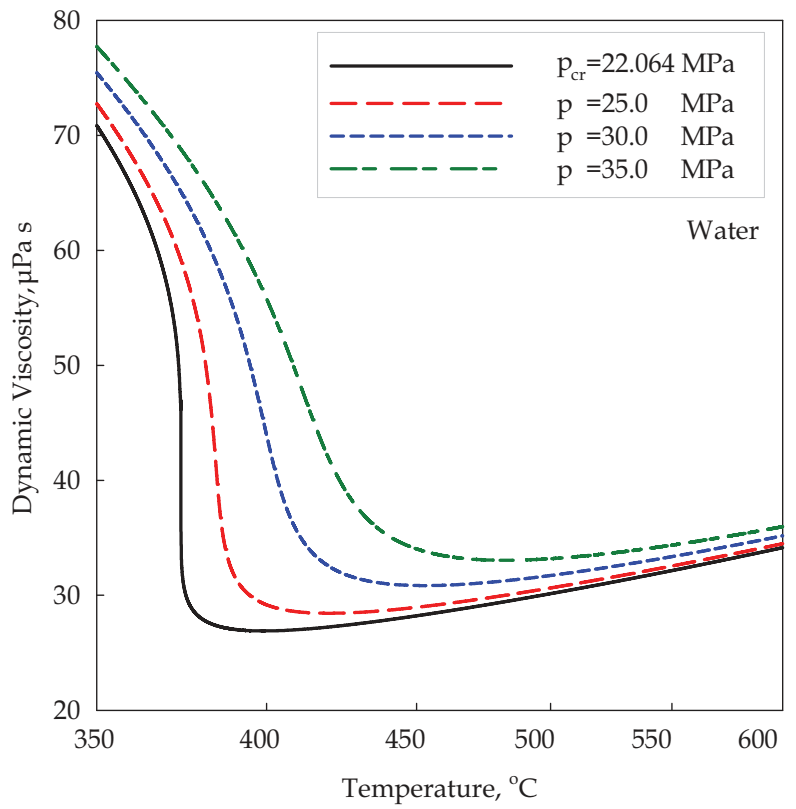

Fig. 6b. Dynamic viscosity vs. Temperature: Water.

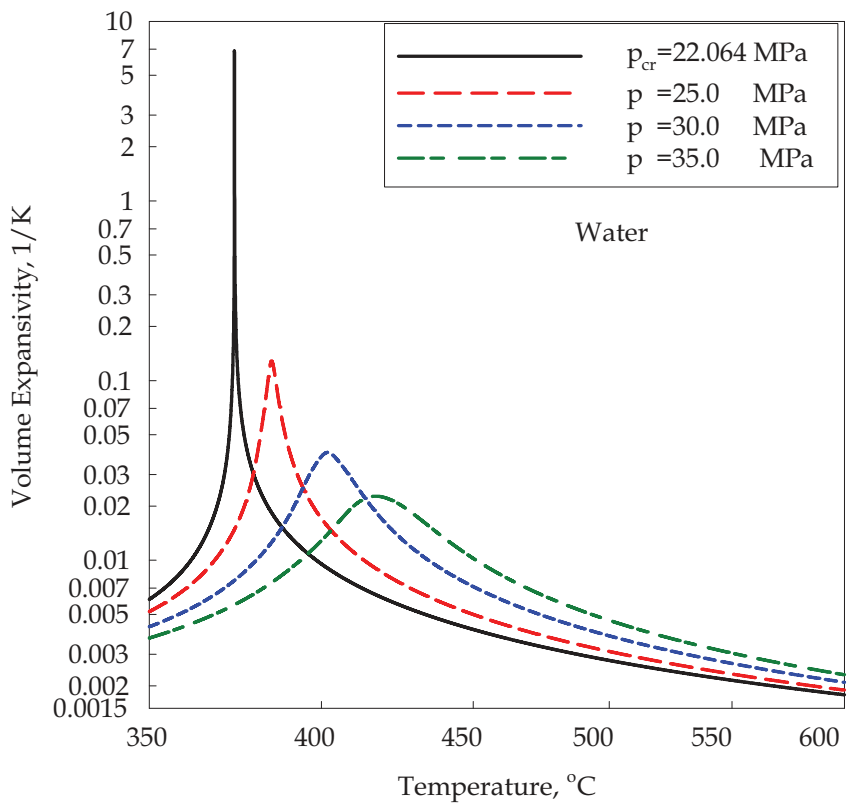

Fig. 6c. Volume expansivity vs. Temperature: Water. 


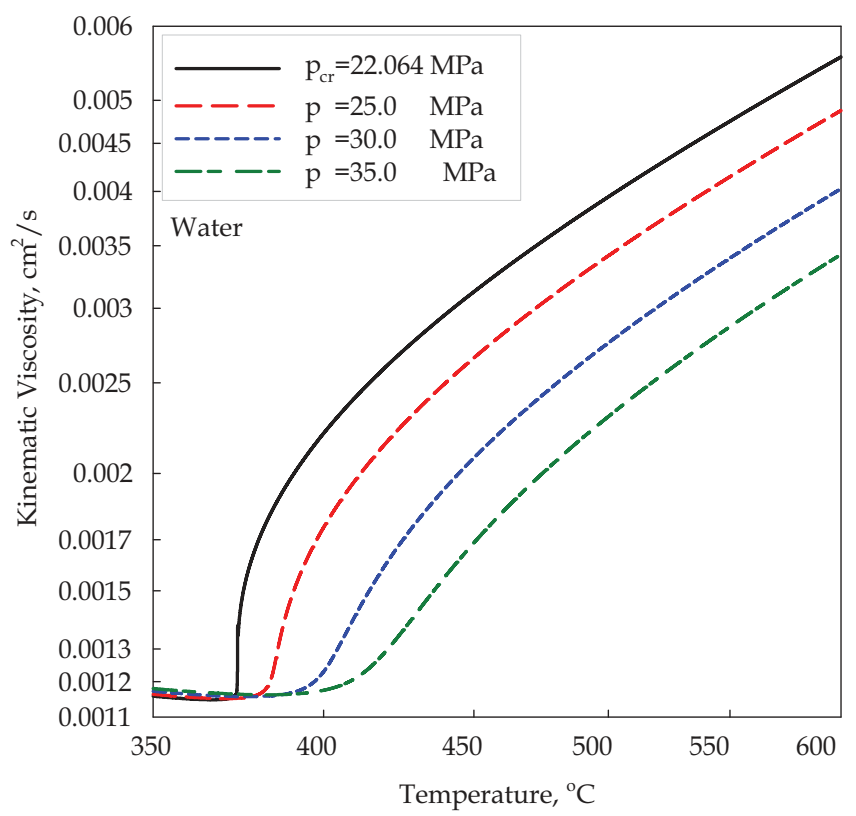

Fig. 6d. Kinematic viscosity vs. Temperature: Water.

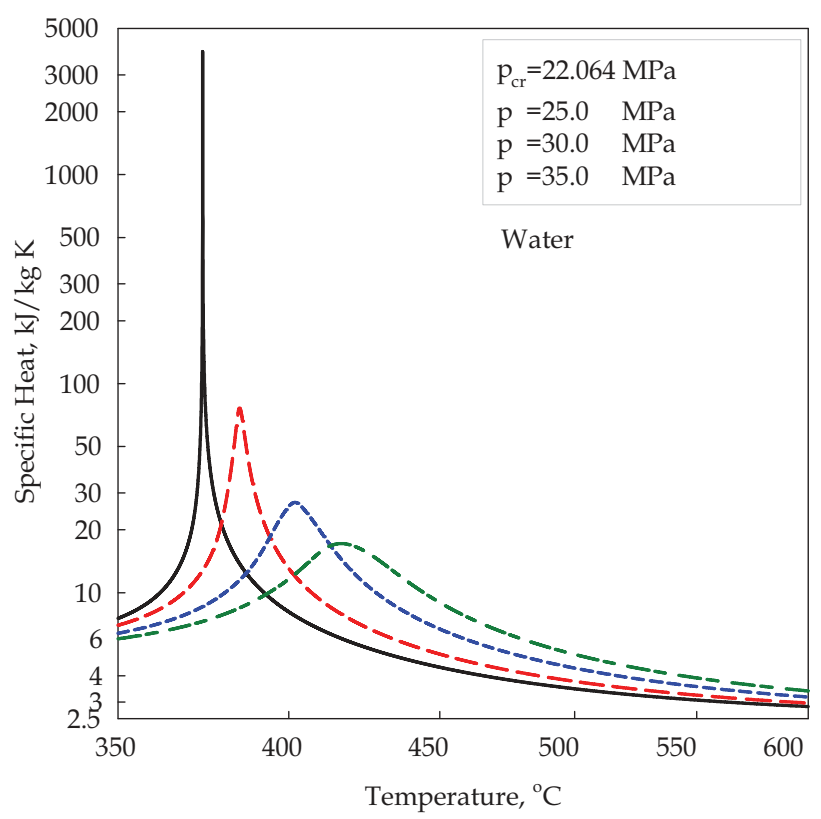

Fig. 6e. Specific heat vs. Temperature: Water. 


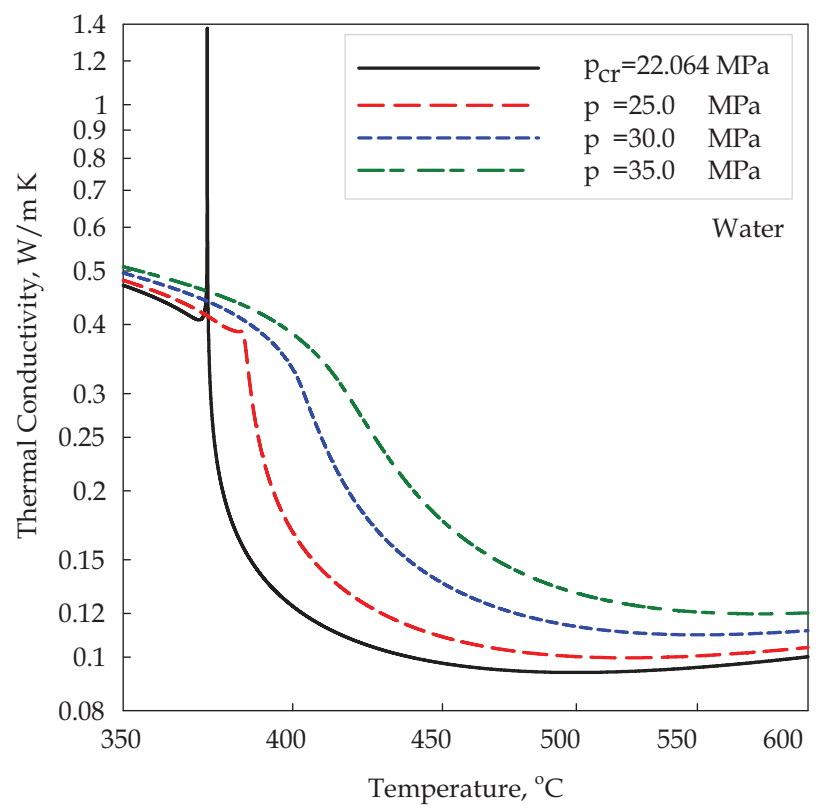

Fig. 6f. Thermal conductivity vs. Temperature: Water.

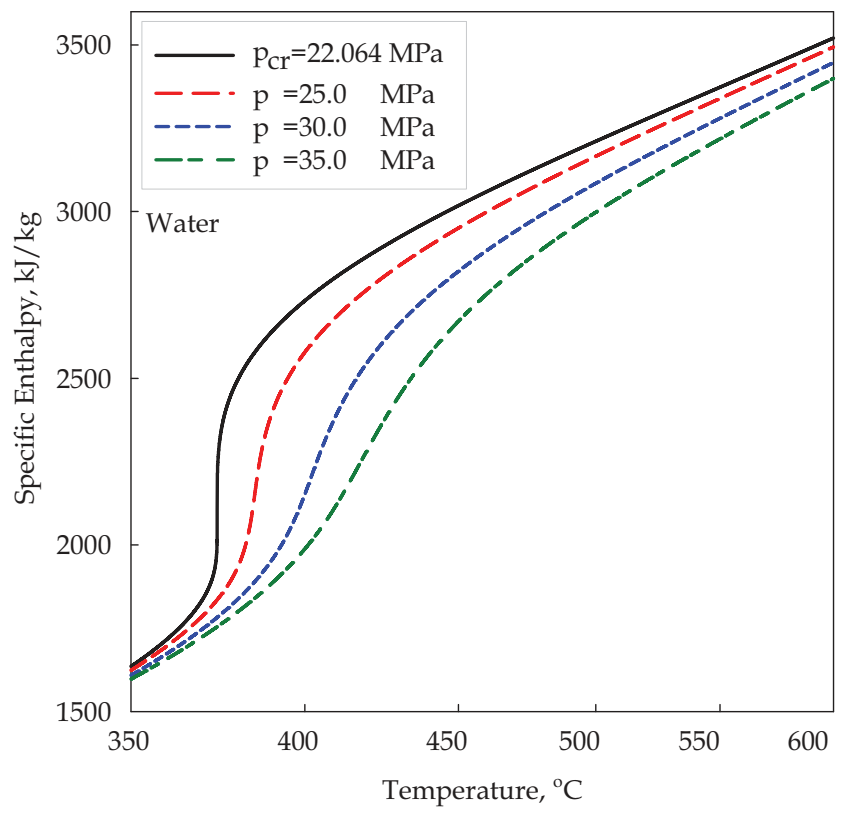

Fig. 6g. Specific enthalpy vs. Temperature: Water. 


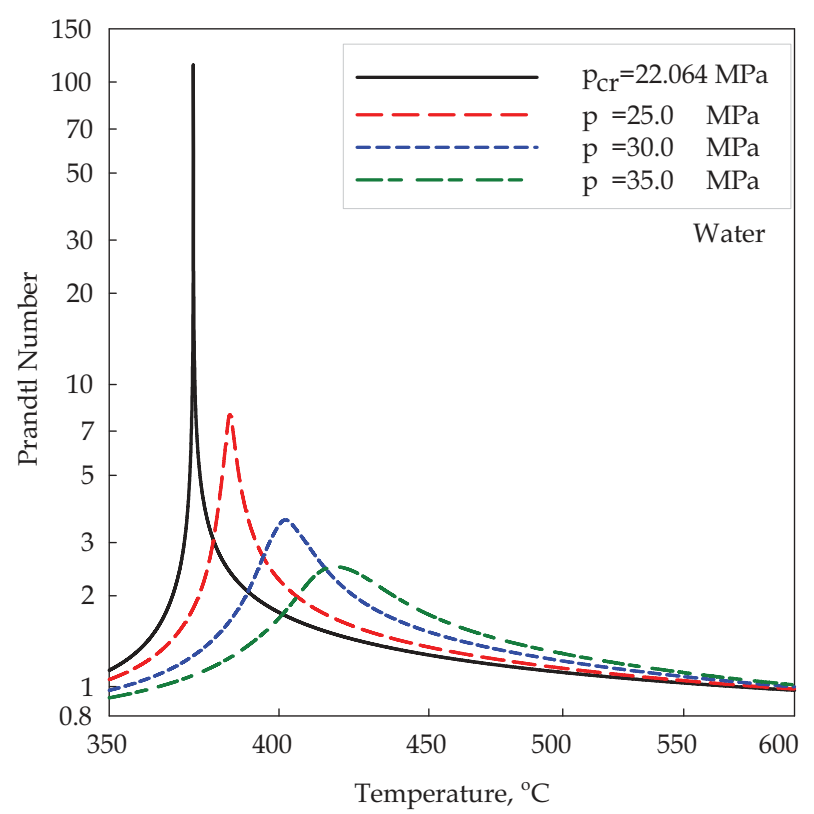

Fig. 6h. Prandtl number vs. Temperature: Water.

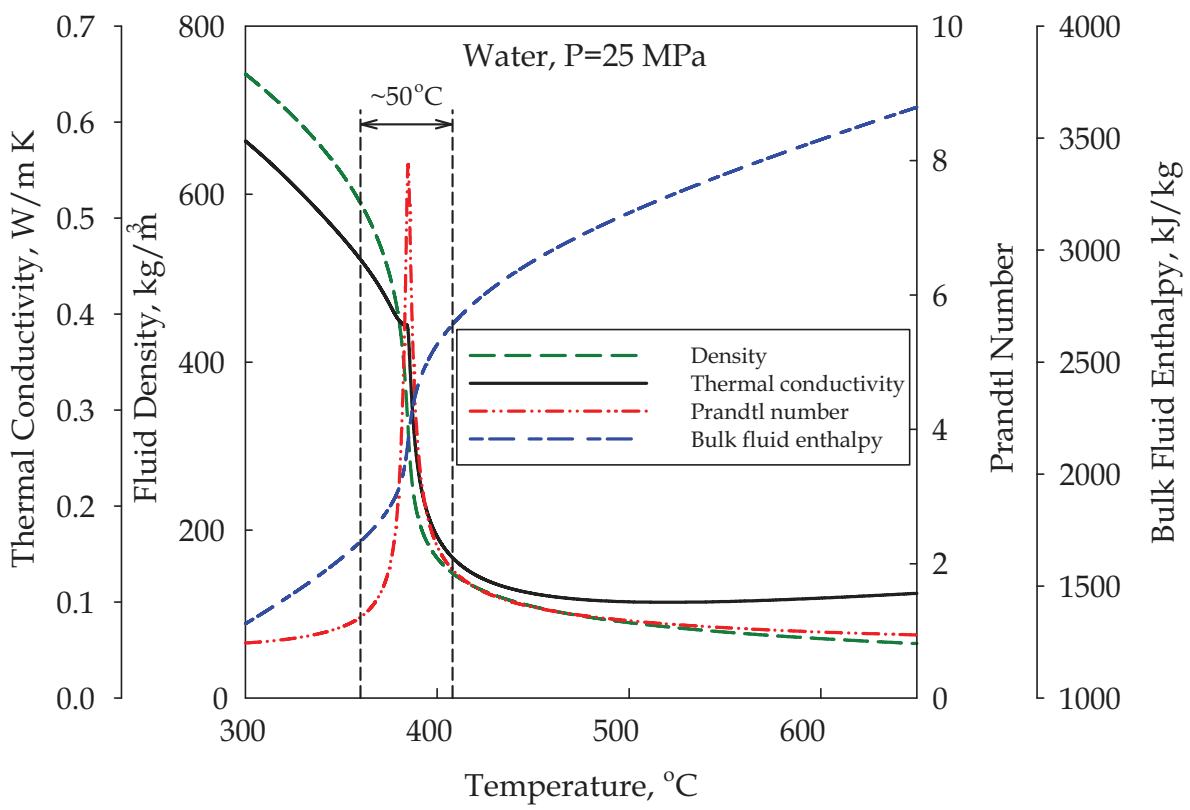

Fig. 7. Variations of selected thermophysical properties of water near pseudocritical point: Pseudocritical region at $25 \mathrm{MPa}$ is about $\pm 25^{\circ} \mathrm{C}$ around pseudocritical point. 


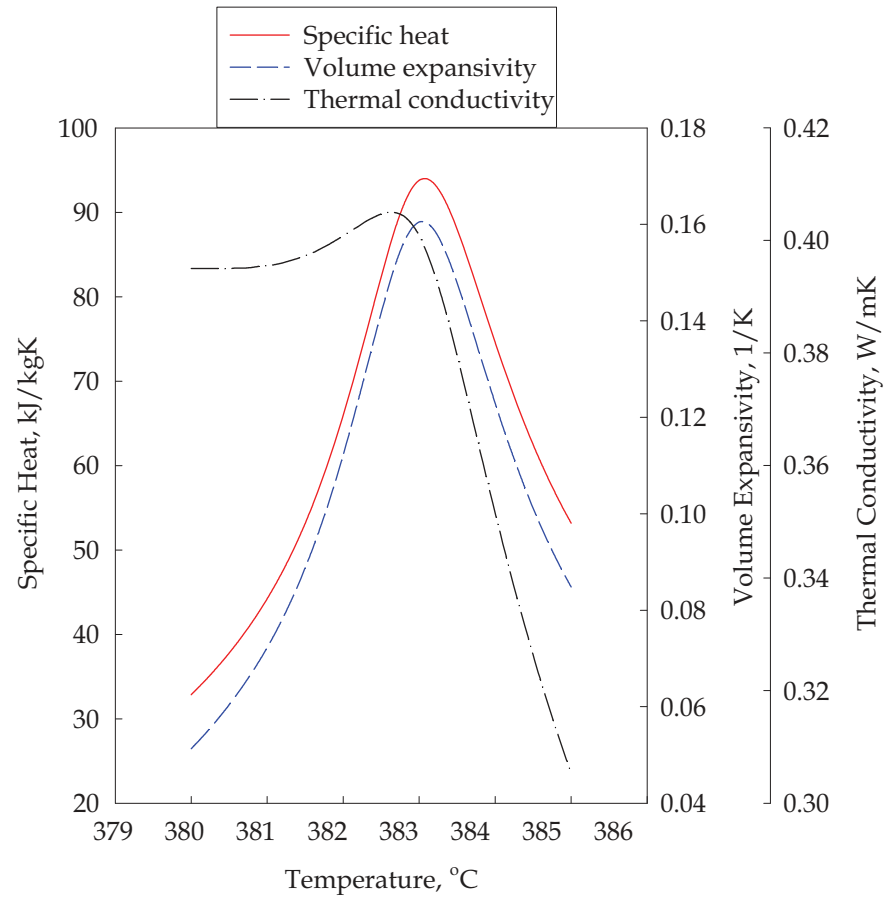

Fig. 8. Specific heat, volume expansivity and thermal conductivity vs. temperature: Water, $P=24.5 \mathrm{MPa}$.

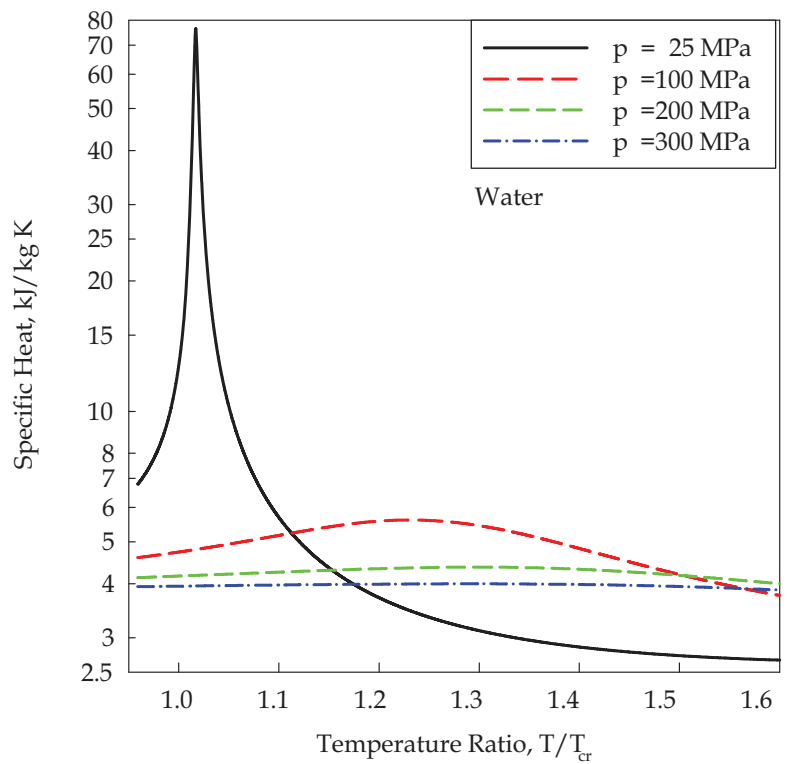

Fig. 9. Specific heat variations at various pressures: Water. 


\begin{tabular}{|c|c|c|}
\hline Pressure, MPa & Pseudocritical temperature, $\mathbf{0}$ C & Peak value of specific heat, kJ/kg.K \\
\hline 23 & 377.5 & 284.3 \\
\hline 24 & 381.2 & 121.9 \\
\hline 25 & 384.9 & 76.4 \\
\hline 26 & 388.5 & 55.7 \\
\hline 27 & 392.0 & 43.9 \\
\hline 28 & 395.4 & 36.3 \\
\hline 29 & 398.7 & 30.9 \\
\hline 30 & 401.9 & 27.0 \\
\hline 31 & 405.0 & 24.1 \\
\hline 32 & 408.1 & 21.7 \\
\hline 33 & 411.0 & 19.9 \\
\hline 34 & 413.9 & 18.4 \\
\hline 35 & 416.7 & 17.2 \\
\hline
\end{tabular}

Table 2. Values of pseudocritical temperature and corresponding peak values of specific heat within wide range of pressures.

\begin{tabular}{|c|c|c|c|c|c|}
\hline $\begin{array}{c}\text { Pressure, } \\
\text { MPa }\end{array}$ & $\begin{array}{c}\text { Pseudocritical } \\
\text { temperature, } \\
{ }^{\circ} \mathrm{C}\end{array}$ & $\begin{array}{c}\text { Temperature, } \\
{ }^{\circ} \mathbf{C}\end{array}$ & $\begin{array}{c}\text { Specific } \\
\text { heat, } \\
\text { keJlkg.K }\end{array}$ & $\begin{array}{c}\text { Volume } \\
\text { expansivity, } \\
\text { 1/K }\end{array}$ & $\begin{array}{c}\text { Thermal } \\
\text { conductivity, } \\
\text { W/m.K }\end{array}$ \\
\hline$p_{c r}=22.064$ & $t_{c r}=374.1$ & - & $\infty$ & $\infty$ & $\infty$ \\
\hline 22.5 & 375.6 & - & 690.6 & 1.252 & 0.711 \\
\hline \multirow{2}{*}{23.0} & - & 377.4 & - & - & 0.538 \\
\hline & 377.5 & - & 284.3 & 0.508 & - \\
\hline \multirow{3}{*}{23.5} & - & 379.2 & - & - & 0.468 \\
\hline & - & 379.3 & - & 0.304 & - \\
\hline & 379.4 & - & 171.9 & - & - \\
\hline \multirow{2}{*}{24.0} & - & 381.0 & - & - & 0.429 \\
\hline & 381.2 & - & 121.9 & 0.212 & - \\
\hline \multirow{3}{*}{24.5} & - & 382.6 & - & - & 0.405 \\
\hline & - & 383.0 & - & 0.161 & - \\
\hline & 383.1 & - & 93.98 & - & - \\
\hline \multirow{3}{*}{25.0} & - & 384.0 & - & - & 0.389 \\
\hline & 384.9 & - & 76.44 & - & - \\
\hline & - & 385.0 & - & 0.128 & - \\
\hline 25.5 & 386.7 & - & 64.44 & 0.107 & no peak \\
\hline 26.0 & 388.5 & - & 55.73 & 0.090 & 0.355 \\
\hline 27.0 & 392.0 & - & 43.93 & 0.069 & 0.340 \\
\hline 28.0 & 395.4 & - & 36.29 & 0.056 & 0.329 \\
\hline 29.0 & 398.7 & - & 30.95 & 0.046 & 0.321 \\
\hline 30.0 & 401.9 & - & 27.03 & 0.039 & 0.316 \\
\hline
\end{tabular}

Table 3. Peak values of specific heat, volume expansivity and thermal conductivity in critical and near pseudocritical points. 
The specific heat of water (as well as of other fluids) has the maximum value at the critical point (see Fig. 6e). The exact temperature that corresponds to the specific-heat peak above the critical pressure is known as the pseudocritical temperature (see Fig. 1 and Table 2). At pressures approximately above $300 \mathrm{MPa}$ (see Fig. 9) a peak (here it is better to say "a hump") in specific heat almost disappears, therefore, such term as a pseudocritical point does not exist anymore. The same applies to the pseudocritical line. It should be noted that peaks in the thermal conductivity and volume expansivity may not correspond to the pseudocritical temperature (see Table 3 and Figure 8).

In early studies, i.e., approximately before 1990, a peak in thermal conductivity was not taken into account. Later, this peak was well established (see Fig. 6f) and included into thermophysical data and software. The peak in thermal conductivity diminishes at about 25.5 MPa for water (see Fig. 6f and Table 3).

In general, crossing the pseudocritical line from left to right (see Fig. 1) is quite similar as crossing the saturation line from liquid into vapour. The major difference in crossing these two lines is that all changes (even drastic variations) in thermophysical properties at supercritical pressures are gradual and continuous, which take place within a certain temperature range (see Fig. 6). On contrary, at subcritical pressures we have properties discontinuation on the saturation line: one value for liquid and another for vapour (see Fig. 10). Therefore, supercritical fluids behave as single-phase substances. Also, dealing with supercritical fluids we apply usually a term "pseudo" in front of a critical point, boiling, film boiling, etc.

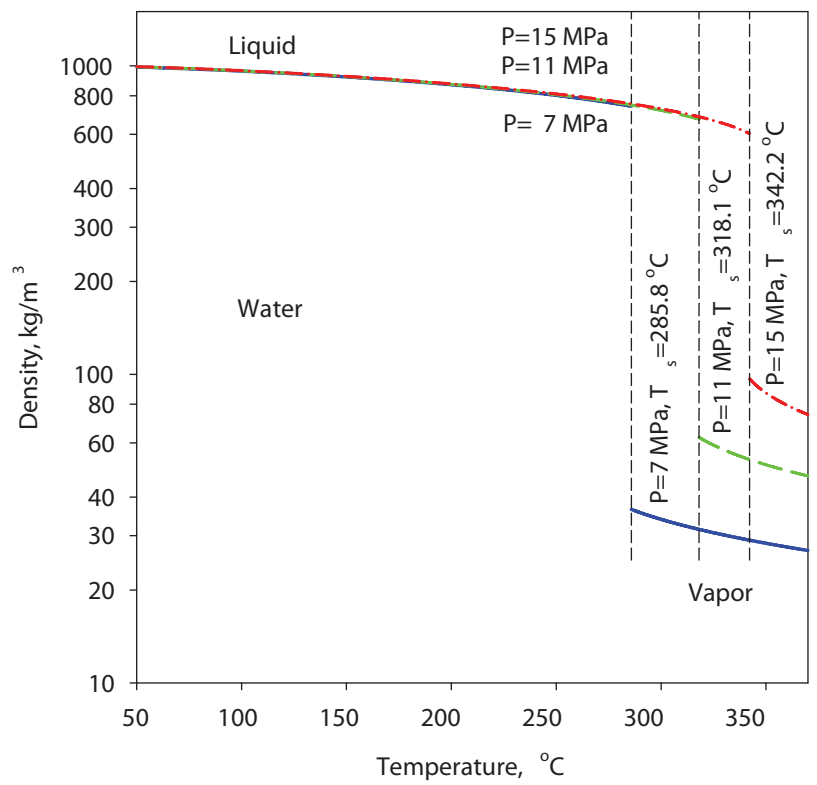

Fig. 10. Density variations at various subcritical pressures for water: Liquid and vapour.

In addition to supercritical-water properties, supercritical properties of R-12 (Richards et al., 2010) are shown in Fig. 11 for reference purposes. Properties of supercritical carbon dioxide, helium and R-134a are shown in Pioro and Duffey (2007). 


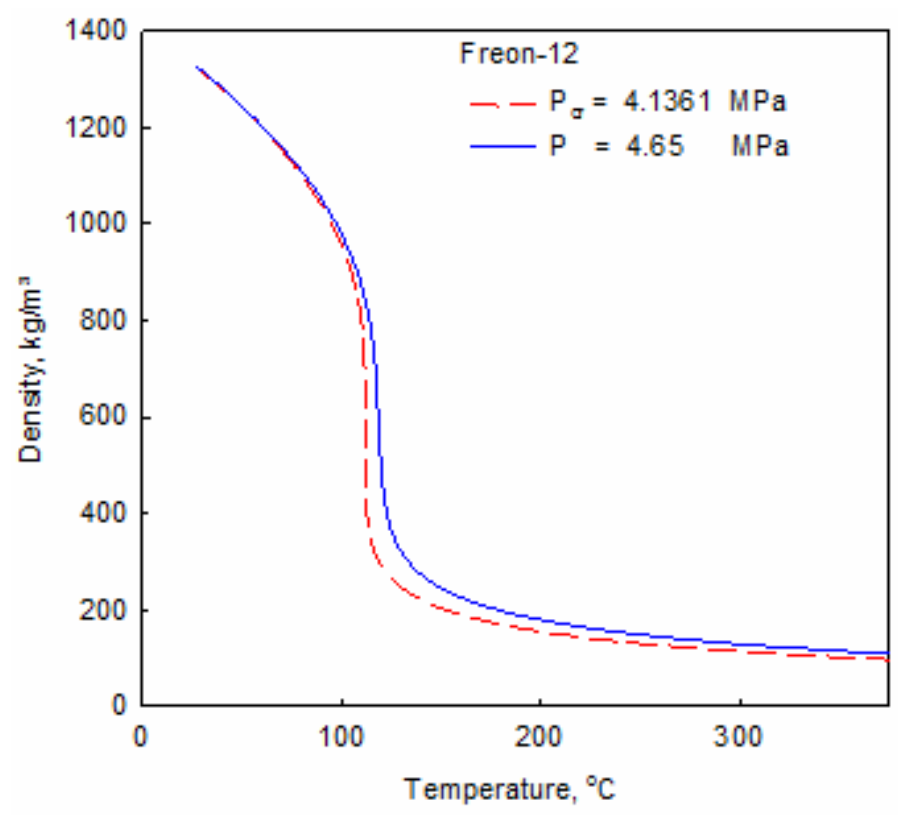

Fig. 11a. Density vs. Temperature: R-12

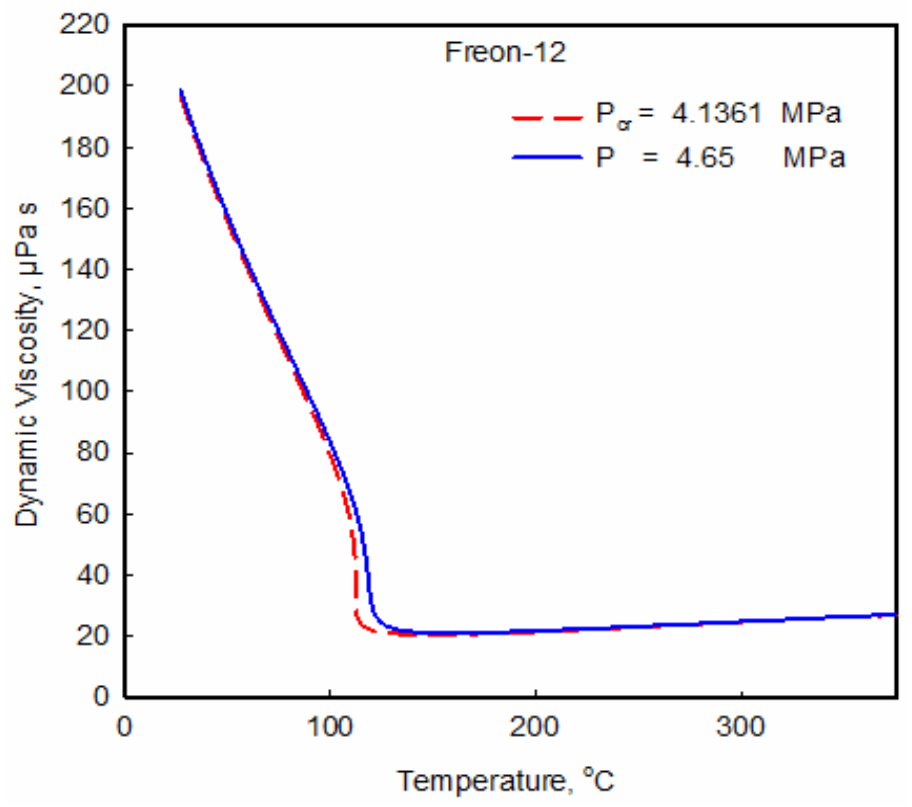

Fig. 11b. Dynamic viscosity vs. Temperature: R-12. 


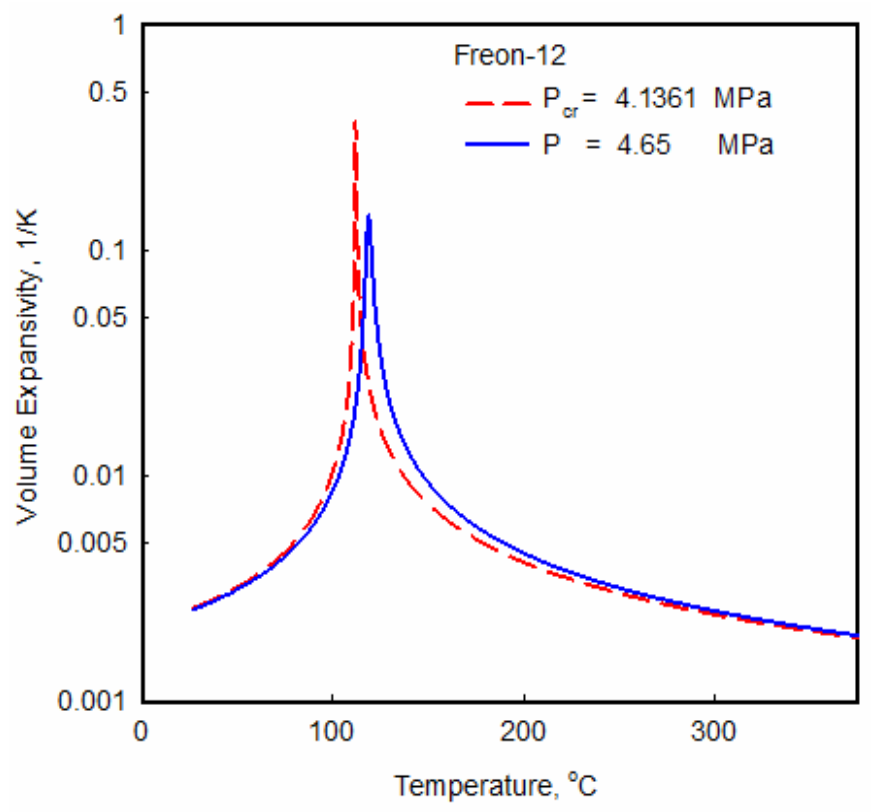

Fig. 11c. Volume expansivity vs. Temperature: R-12.

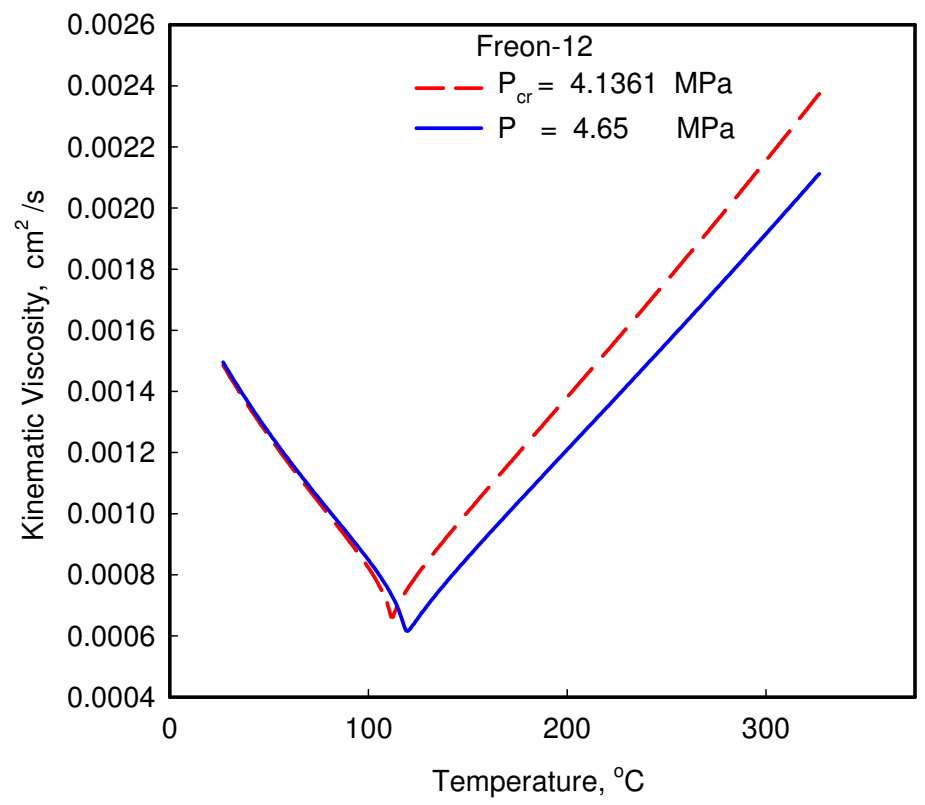

Fig. 11d. Kinematic viscosity vs. Temperature: R-12. 


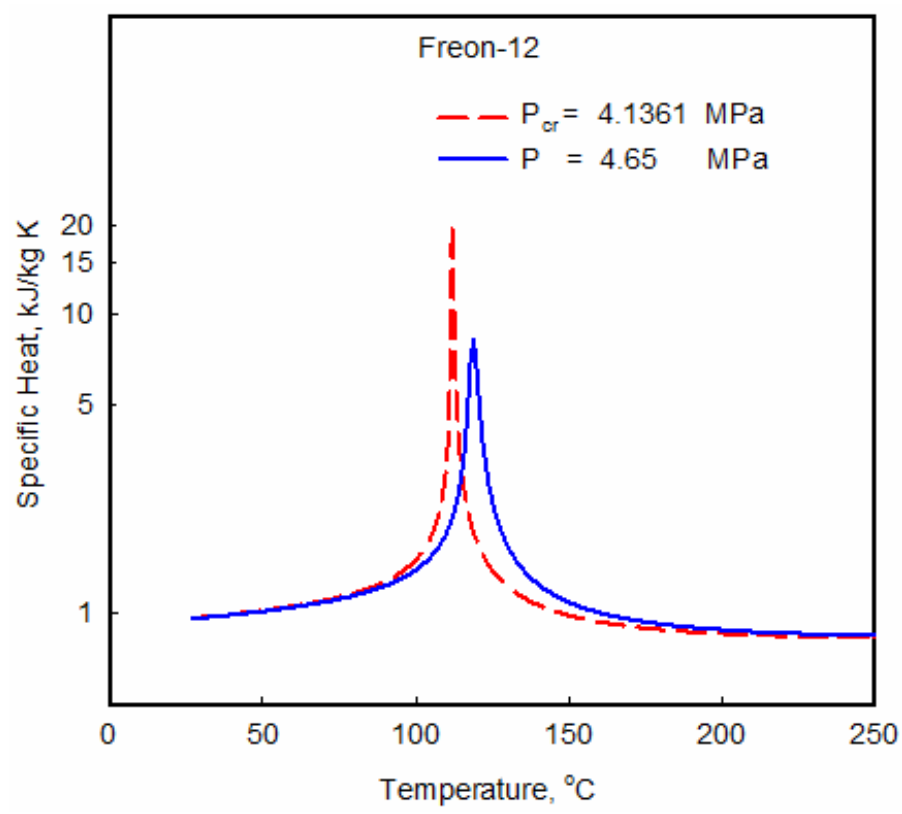

Fig. 11e. Specific heat vs. Temperature: R-12.

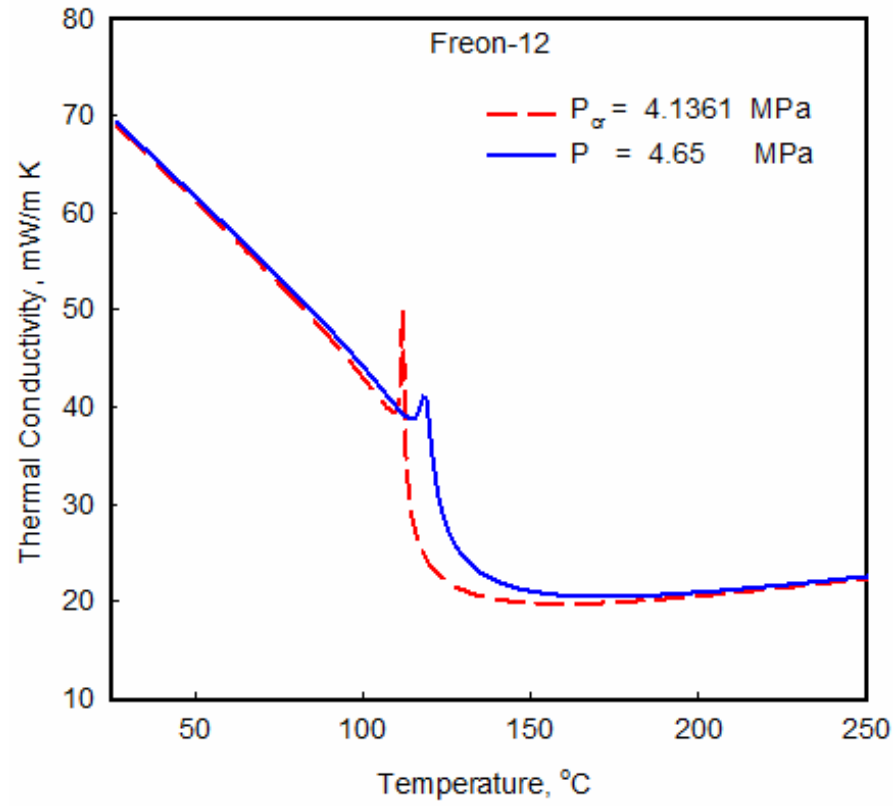

Fig. 11f. Thermal conductivity vs. Temperature: R-12. 


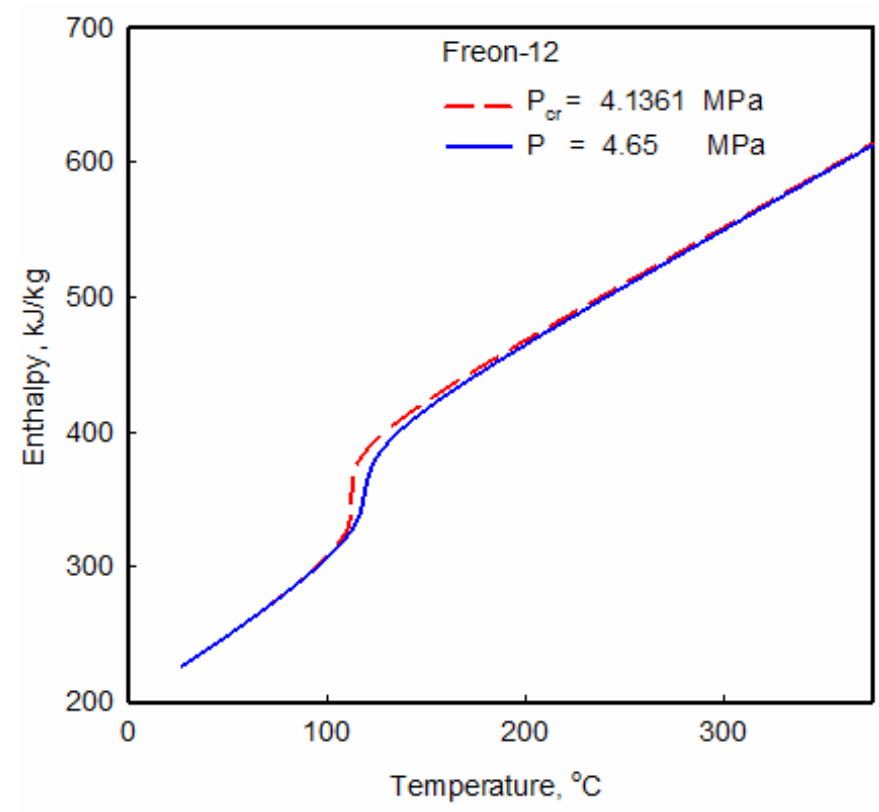

Fig. 11g. Specific enthalpy vs. Temperature.

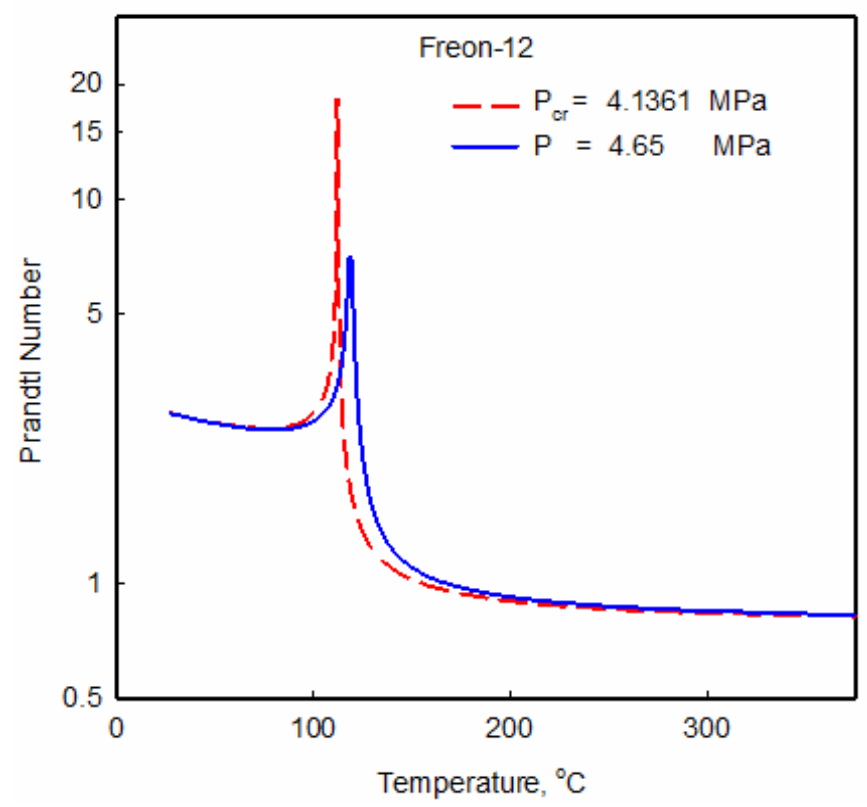

Fig. 11h. Prandlt number vs. Temperature: R-12. 


\section{Acknowledgements}

Financial supports from the NSERC Discovery Grant and NSERC/NRCan/AECL Generation IV Energy Technologies Program are gratefully acknowledged.

\section{Nomenclature}

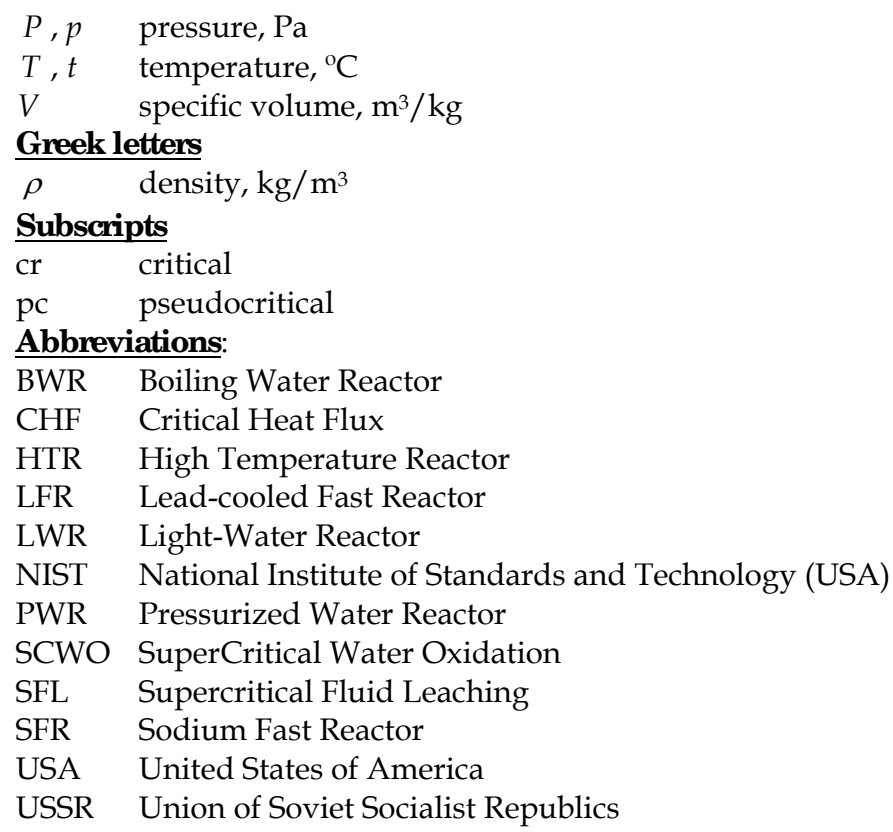

\section{Reference}

International Encyclopedia of Heat \& Mass Transfer, 1998. Edited by G.F. Hewitt, G.L. Shires and Y.V. Polezhaev, CRC Press, Boca Raton, FL, USA, pp. 1112-1117 (Title "Supercritical heat transfer").

Kruglikov, P.A., Smolkin, Yu.V. and Sokolov, K.V., 2009. Development of Engineering Solutions for Thermal Scheme of Power Unit of Thermal Power Plant with Supercritical Parameters of Steam, (In Russian), Proc. of Int. Workshop "Supercritical Water and Steam in Nuclear Power Engineering: Problems and Solutions", Moscow, Russia, October 22-23, 6 pages.

Levelt Sengers, J.M.H.L., 2000. Supercritical Fluids: Their Properties and Applications, Chapter 1, in book: Supercritical Fluids, editors: E. Kiran et al., NATO Advanced Study Institute on Supercritical Fluids - Fundamentals and Application, NATO Science Series, Series E, Applied Sciences, Kluwer Academic Publishers, Netherlands, Vol. 366, pp. 1-29.

National Institute of Standards and Technology, 2007. NIST Reference Fluid Thermodynamic and Transport Properties-REFPROP. NIST Standard Reference Database 23, Ver. 8.0. Boulder, CO, U.S.: Department of Commerce. 
Oka, Y, Koshizuka, S., Ishiwatari, Y., and Yamaji, A., 2010. Super Light Water Reactors and Super Fast Reactors, Springer, 416 pages.

Pioro, I.L., 2008. Thermophysical Properties at Critical and Supercritical Pressures, Section 5.5.16 in Heat Exchanger Design Handbook, Begell House, New York, NY, USA, 14 pages.

Pioro, I.L. and Duffey, R.B., 2007. Heat Transfer and Hydraulic Resistance at Supercritical Pressures in Power Engineering Applications, ASME Press, New York, NY, USA, 328 pages.

Pioro, L.S. and Pioro, I.L., Industrial Two-Phase Thermosyphons, 1997, Begell House, Inc., New York, NY, USA, 288 pages.

Richards, G., Milner, A., Pascoe, C., Patel, H., Peiman, W., Pometko, R.S., Opanasenko, A.N., Shelegov, A.S., Kirillov, P.L. and Pioro, I.L., 2010. Heat Transfer in a Vertical 7Element Bundle Cooled with Supercritical Freon-12, Proceedings of the 2nd CanadaChina Joint Workshop on Supercritical Water-Cooled Reactors (CCSC-2010), Toronto, Ontario, Canada, April 25-28, 10 pages. 


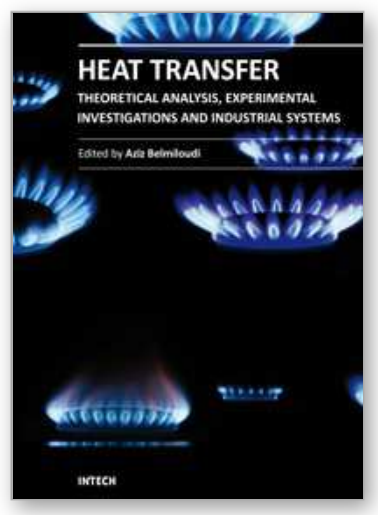

\author{
Heat Transfer - Theoretical Analysis, Experimental Investigations \\ and Industrial Systems \\ Edited by Prof. Aziz Belmiloudi
}

ISBN 978-953-307-226-5

Hard cover, 654 pages

Publisher InTech

Published online 28, January, 2011

Published in print edition January, 2011

Over the past few decades there has been a prolific increase in research and development in area of heat transfer, heat exchangers and their associated technologies. This book is a collection of current research in the above mentioned areas and discusses experimental, theoretical and calculation approaches and industrial utilizations with modern ideas and methods to study heat transfer for single and multiphase systems. The topics considered include various basic concepts of heat transfer, the fundamental modes of heat transfer (namely conduction, convection and radiation), thermophysical properties, condensation, boiling, freezing, innovative experiments, measurement analysis, theoretical models and simulations, with many real-world problems and important modern applications. The book is divided in four sections : "Heat Transfer in Micro Systems", "Boiling, Freezing and Condensation Heat Transfer", "Heat Transfer and its Assessment", "Heat Transfer Calculations", and each section discusses a wide variety of techniques, methods and applications in accordance with the subjects. The combination of theoretical and experimental investigations with many important practical applications of current interest will make this book of interest to researchers, scientists, engineers and graduate students, who make use of experimental and theoretical investigations, assessment and enhancement techniques in this multidisciplinary field as well as to researchers in mathematical modelling, computer simulations and information sciences, who make use of experimental and theoretical investigations as a means of critical assessment of models and results derived from advanced numerical simulations and improvement of the developed models and numerical methods.

\title{
How to reference
}

In order to correctly reference this scholarly work, feel free to copy and paste the following:

Igor Pioro and Sarah Mokry (2011). Thermophysical Properties at Critical and Supercritical Pressures, Heat Transfer - Theoretical Analysis, Experimental Investigations and Industrial Systems, Prof. Aziz Belmiloudi (Ed.), ISBN: 978-953-307-226-5, InTech, Available from: http://www.intechopen.com/books/heat-transfer-theoreticalanalysis-experimental-investigations-and-industrial-systems/thermophysical-properties-at-critical-andsupercritical-pressures

\section{INTECH}

open science | open minds

\author{
InTech Europe \\ University Campus STeP Ri \\ Slavka Krautzeka 83/A
}

\section{InTech China}

Unit 405, Office Block, Hotel Equatorial Shanghai

No.65, Yan An Road (West), Shanghai, 200040, China 
51000 Rijeka, Croatia

Phone: +385 (51) 770447

Fax: +385 (51) 686166

www.intechopen.com
中国上海市延安西路65号上海国际贵都大饭店办公楼 405 单元 Phone: +86-21-62489820

Fax: +86-21-62489821 
(C) 2011 The Author(s). Licensee IntechOpen. This chapter is distributed under the terms of the Creative Commons Attribution-NonCommercialShareAlike-3.0 License, which permits use, distribution and reproduction for non-commercial purposes, provided the original is properly cited and derivative works building on this content are distributed under the same license. 